\title{
O planejamento pedagógico na Educação Infantil: as percepções de professores, diretores e coordenadores pedagógicos
}

\section{Pedagogical planning in early childhood education: perceptions of teachers, principals and pedagogical coordinators}

\author{
Beatriz de Oliveira Abuchaim é graduada em Psicologia pela \\ PUC-RS, mestre em Educação pela PUC-RS e doutora em \\ Educação:Currículo pela PUC-SP. Trabalha como pesquisadora na \\ Fundação Carlos Chagas, em São Paulo.
}

\section{Contato: biaabuchaim@hotmail.com}

\section{Resumo}

Este artigo analisa a importância do planejamento na Educação Infantil, partindo das percepções de professores, diretores e coordenadores pedagógicos. São apresentados dados de um estudo de caso que buscou descrever como o currículo era transposto para o planejamento e deste para o cotidiano dos grupos de crianças, em duas escolas municipais de São Paulo. Foram realizadas entrevistas, observações do cotidiano e análise de documentos. Concluiu-se que o planejamento é valorizado pelos entrevistados, pois garante uma prática mais refletida e fundamentada. 0 planejamento demanda três ações do professor: escrever sobre o vivido e o projeto futuro; debater com os colegas sobre o processo e pesquisar sobre os temas e as atividades que pretende realizar.

Palavras-chave: Educação Infantil. Planejamento. Currículo.

\section{Abstract}

This paper analyses the importance of pedagogical planning in early childhood education, based on the perceptions of teachers, principals and pedagogical coordinators. Data from a case study are presented. The research aimed 
to describe how the curriculum was transposed into a pedagogical planning, and then into the daily life of groups of children in two public schools of São Paulo. Interviews, daily observations and document analysis were conducted. The results show that the activity of planning is considered important by the interviewees, as it guarantees a more careful and structured practice. The planning requires three actions of the teacher: to write about what was experienced and the future project; to discuss with colleagues about the method, and to research on the topics and activities he wants to accomplish.

Keywords: Early Childhood Education. Pedagogical Planning. Preschool Curriculum.

\section{Introdução}

0 foco deste artigo é discutir a importância da atividade de planejamento no trabalho cotidiano do professor de Educação Infantil. Para tal, serão explorados dados da tese de doutorado Currículo, planejamento pedagógico e cotidiano na pré-escola: do prescritoplanejado ao experienciado-vivido (ABUCHAIM, 2012) que teve por objetivo descrever como acontecia a transposição do prescrito nos documentos curriculares para o planejamento pedagógico do professor, e deste para o cotidiano das crianças em duas instituições públicas de Educação Infantil do município de São Paulo.

Quando da elaboração do projeto de tal estudo, partiu-se da premissa de que o planejamento seria uma atividade fundamental para o professor, no sentido de oportunizar momentos de reflexão sobre as propostas curriculares e o cotidiano. 0 planejamento poderia ser considerado, assim, uma atividade mediadora do professor e uma das principais ferramentas da prática docente, pois: facilita o diálogo do professor com o currículo e deste com a prática; propicia ao professor um momento de reflexão sobre o trabalho realizado e a realizar e permite a expressão da própria identidade profissional do professor e de seu grupo de crianças. Desse modo, o planejamento possibilita o aperfeiçoamento da prática pedagógica, uma vez que pode ser usado tanto para projetar quanto para avaliar essa prática.

Na bibliografia nacional sobre Educação Infantil pouco é mencionado sobre a atividade de planejamento, como se esse processo fosse inerente ao ato de ser professor ou como se na Educação Infantil a atividade de planejamento fosse de menor 
importância. Existem muitos livros, artigos e pesquisas que tratam de concepções teóricas e de modelos pedagógicos, mas são encontradas poucas reflexões sobre as estratégias usadas para colocar em prática tais aportes. Reconhece-se a produção de algumas autoras que têm contribuído especificamente para 0 tema, como Ostetto (2000; 2015), Guimarães (2005), Redin (2007) e Corsino (2009).

Durante os vários anos em que atuei como psicóloga educacional e pesquisadora em instituições de Educação Infantil observei que, em muitas situações, independentemente do contexto (social, econômico, cultural) em que a escola se inseria, o planejamento realizado pelos professores era feito de forma precária, de modo que muitas atividades desenvolvidas eram totalmente improvisadas, não contemplavam seus interesses e pouco contribuíam para os processos de aprendizagem e de desenvolvimento das crianças. Essa realidade era determinada por uma série de condições e situações por mim detectadas: a instituição não previa horas de planejamento para os professores; o planejamento era contado como hora remunerada, mas deveria ser feito em casa; o planejamento, mesmo quando realizado na instituição, era feito solitariamente; em muitas escolas não havia a figura de um coordenador pedagógico para orientar essa atividade; os professores não tinham acesso aos documentos curriculares nacionais, municipais e da instituição ou não tinham interesse em conhecê-los; e, por último, e infelizmente o mais frequente dos motivos: os professores não sabiam planejar atividades que estivessem de acordo com suas intenções pedagógicas e com os interesses do grupo de crianças.

Por tudo isso, pareceu-me interessante investigar como ocorria a atividade de planejamento (quem eram os envolvidos, em que momento ocorria e como os interesses das crianças eram levados em conta) e quais eram as percepções de professores, coordenadores pedagógicos e diretores a respeito dela, em duas Escolas Municipais de Educação Infantil de São Paulo, selecionadas por apresentarem boas condições de infraestrutura e materiais, proposta pedagógica (PP) consolidada e alguma estabilidade no quadro de funcionários.

Comparando com as redes de ensino de outras prefeituras (ver dados dos estudos: CAMPOS, et al 2010 e CAMPOS, et al, 2012 ${ }^{1}$ ), as escolas de São Paulo têm uma situação muito favorável, não só por terem horários para reuniões de planejamento e formação dos professores, mas também pelo fato de cada instituição contar com um profissional para atuar na coordenação pedagógica. As
1. Esse estudo investigou seis capitais brasileiras no que diz respeito à gestão da Educação Infantil. Concluiu-se que as iniciativas de formação continuada variavam muito e nem sempre estavam articuladas às reais necessidades dos profissionais. Em dois municípios não são previstas horas de planejamento remuneradas aos professores. Além disso, não são todas as redes que preveem a presença do coordenador pedagógico nas unidades. 
professoras da rede municipal de São Paulo podem escolher a sua jornada de trabalho. Quando optam pela integral, ganham a garantia por lei de momentos semanais de planejamento e formação dentro da escola.

Na sequência do texto, serão expostos os conceitos teóricos utilizados como base para a formulação do problema de pesquisa e a metodologia empregada no estudo. Ao final, os resultados serão apresentados e discutidos com fundamentação em aporte teórico pertinente ao tema.

\section{Referencial teórico}

A fim de discutir as articulações entre currículo, planejamento e cotidiano, adotei como ponto de partida o conceito de currículo proposto por Gimeno Sacristán $(2008 ; 2007)$ e as concepções de planejamento exploradas por Redin (2007) e Corsino (2009).

Gimeno Sacristán (2008) descreve o currículo como uma práxis ${ }^{2}$ que se constrói a partir de orientações escritas, mas que só existe na realidade concreta de aprendizagem dentro das escolas. A construção do currículo

\begin{abstract}
não pode ser entendida separadamente das condições reais de seu desenvolvimento e, por isso mesmo, entender o currículo num sistema educativo requer prestar atenção às práticas políticas e administrativas que se expressam no seu desenvolvimento, às condições estruturais, organizativas, materiais, dotação de professorado, à bagagłem de ideias e significado que the dão forma e que o modelam em sucessivos passos de transformação (GIMENO SACRISTÁN, 2008, p. 21).
\end{abstract}

Nessa perspectiva, o currículo pode ser entendido como campo de interação entre práticas e ideias. Gimeno Sacristán (2007) salienta que ensinar não é uma atividade meramente instrumental, que coloca em prática um projeto curricular com objetivos e conteúdos previamente estabelecidos. Ensinar é um conjunto de práticas nas quais se concretiza o que está previamente instituído no currículo formal. Assim sendo, o próprio currículo deve ser concebido como um projeto educativo redefinido na prática escolar, quando alunos e professores ressignificam os conteúdos previamente estabelecidos. Essa posição do autor aproxima a área da didática à do currículo, já que técnica e conteúdo estão intrinsecamente relacionados no ato de ensinar. 0 currículo, então, só existe de fato quando ele sai do papel e acontece.
2. A concepção de "práxis" utilizada nesse trabalho não se limita ao significado de "prática" simplesmente, mas expressa o processo de ação transformadora, fundamentada na reflexão, em que ação e reflexão ocorrem simultaneamente. De acordo com Bottomore (1988, p. 292): "A expressão práxis refere-se, em geral, a ação, a atividade, e, no sentido que the atribui Marx, à atividade livre, universal, criativa e auto-criativa, por meio da qual o homem cria (faz, produz), e transforma (conforma) seu mundo humano e histórico e a si mesmo". Seguindo os preceitos marxistas, Freire (1987) define a práxis como "reflexão e ação dos homens sobre o mundo para transformá-lo" e vê nela a possibilidade de superação da "contradição opressor-oprimidos". 
Desse modo, o currículo é muito mais do que o prescrito em documentos oficiais. Ele envolve tudo o que acontece no processo educativo, incluindo os planos dos professores e sua execução; por isso é uma construção social, historicamente circunscrita e cotidianamente transformada. No cotidiano é que o professor repensa a sua prática, planeja ações, sofre influências dos mais diversos grupos e torna possível a transposição do currículo no planejamento, e deste para a prática do dia a dia com seu grupo de crianças. Entra em jogo sua capacidade de harmonizar suas intenções pedagógicas com os interesses das crianças, certamente passando por sua capacidade de escutá-las e de respeitar as suas opiniões.

Gimeno Sacristán (2008, p. 105) afirma que, ao planejar as atividades, os professores se lançam em uma tentativa de traduzir o currículo, de modo a torná-lo factível. "O professor é um agente ativo muito decisivo na concretização dos conteúdos e significados dos currículos, moldando a partir de sua cultura profissional qualquer proposta que lhe é feita."

Redin (2007, p. 90) aponta que o ato de planejar é importante, pois permite que o professor reveja suas práticas e os princípios norteadores de seu trabalho. É fundamental, para isso, que o professor tenha registrado e documentado o trabalho desenvolvido com as crianças. Sendo assim, para essa autora, planejar é refletir, em um processo constante de "reflexão-projeção-reflexão".

Desse modo, o planejamento do professor tem um papel central no processo de mediação entre o prescrito no currículo e o cotidiano, uma vez que é o momento de reflexão do professor sobre a sua prática (o que vem acontecendo) e suas intenções (o que projeta acontecer) (REDIN, 2007).

0 conceito de planejamento proposto por Corsino (2009) vai ao encontro dessas ideias. A autora aponta quatro características a respeito dele: o inacabamento (nunca pode ser dado como acabado, pois é no confronto com a realidade que ele ganha novas dimensões); a participação (entendido como um processo coletivo e participativo não centrado na professora, permitindo o protagonismo das crianças); a previsibilidade e a imprevisibilidade (pode conter uma previsão em relação a algumas reações, necessidades e aprendizagens das crianças; outras só vão se mostrar quando o planejamento for posto em ação) e a continuidade e o encadeamento (pode articular as diversas áreas do conhecimento, concebendo o processo de aprendizagem como integrador e não fragmentador). 


\section{Metodologia}

Nesta pesquisa optou-se pela metodologia do estudo de caso, pois se buscou analisar uma unidade dentro de um contexto mais amplo com o fim de descrevê-la de forma a contemplar toda a sua complexidade.

De acordo com Yin (2005), o estudo de caso é a estratégia mais adequada quando as questões de pesquisa envolvem "como" e "por que", e quando o objeto de estudo é um fenômeno inserido na realidade atual, sendo que o pesquisador não possui meios de controlar sua evolução. Dessa forma, esse método ajuda a compreensão de fenômenos sociais complexos, pois é uma investigação que preserva "as características holísticas e significativas dos acontecimentos da vida real” (p. 20).

Assim sendo, procurou-se descrever detalhadamente o contexto de duas escolas de Educação Infantil (EMEls) da rede municipal de educação de São Paulo, de modo a compreender as ações e percepções dos sujeitos acerca do foco do estudo (a transposição do currículo para o cotidiano, mediado pelo planejamento). Para isso, foram utilizadas várias fontes de evidência: observações do cotidiano de quatro turmas de pré-escola; análise de documentos, tais como as propostas pedagógicas das escolas e os planos dos professores e entrevistas com a supervisora da Diretoria Regional de Educação, duas diretoras, duas coordenadoras pedagógicas e cinco professores. É importante mencionar que foram atribuídos nomes fictícios aos sujeitos e às instituições, a fim de assegurar seu anonimato, seguindo as orientações do Comitê de Ética da Pontifícia Universidade Católica de São Paulo.

Os dados obtidos foram analisados conjuntamente, pelo método de análise de conteúdo (BARDIN, 1977), e organizados em quatro categorias: 1. Currículos e projetos pedagógicos das unidades; 2. A atividade de planejar e os planos escritos dos professores; 3 . Os grupos e suas atividades cotidianas e 4 . As estratégias de registro e documentação utilizadas pelos professores e pelas instituições.

Como mencionado anteriormente, este texto se centra na apresentação de dados organizados na categoria 2, "a atividade de planejar e os planos escritos dos professores".

\section{Discussão dos resultados}

A análise de conteúdo tanto dos planos dos professores quanto das entrevistas com professores, coordenadores pedagógicos 
e diretores a respeito do tema "planejamento" gerou quatro subcategorias. A primeira tinha como tema a atividade em si de planejar, como ela acontece, em que momento, quem são os envolvidos. A segunda tratava do repertório do professor para elaborar o planejamento, levando em conta sua trajetória de vida e profissional. A terceira descrevia a importância dada pelos profissionais entrevistados à atividade de planejamento do professor, as dificuldades encontradas em sua elaboração e o que eles consideram ser um bom planejamento. Por último, foram explorados os planos dos professores, não só no sentido de analisar os documentos, mas também de explicitar como o planejamento era pensado ao longo do tempo.

A partir da exploração das ideias dos entrevistados divididas nessas categorias de análise, os principais achados foram sintetizados em seis asserções acerca do planejamento. Essas asserções serão apresentadas a seguir, ilustradas com falas dos participantes e discutidas à luz de bibliografia especializada.

\section{0 planejamento é a linha norteadora do trabalho do professor e garante a boa qualidade de seu trabalho.}

"Planejamento te dá uma linha, uma sequência. Você não trabalha no improviso." Aline, professora.

"Eu não sei se dá para você ir para uma sala de aula sem planejar nada. Não sei responder, acho que fica tudo no 'oba oba', não dá. Planejar é projetar a sua intenção. Se você não planeja, as coisas podem não acontecer." Roberta, diretora.

"Sem planejamento o professor não consegue ter boa qualidade no seu trabalho." Madalena, professora.

Esses trechos de falas dos entrevistados revelam a importância que eles dão à atividade de planejamento. Todos concordaram que o trabalho pedagógico não pode ser realizado sem que haja um plano, uma linha mestra que norteie as ações do professor a cada dia e ao longo das semanas e dos meses. 0 "improviso" apontado por Aline, que emana de uma prática não planejada, revela o profissionalismo contido na ação planejada. Quero dizer: ter um plano de trabalho permite ao professor maximizar a sua atuação com o grupo de crianças, já que pensou os propósitos e os meios de suas intervenções.

0 professor de Educação Infantil, como qualquer outro 
profissional, necessita pensar e organizar suas ações, pois sem isso ele não consegue ter uma visão de conjunto de seu trabalho e noção de onde se encontra na busca de seus objetivos propostos. "O pecado não está em estruturar o trabalho feito com as crianças, mas em se 'apegar' demais a essa estrutura e planejamento como fins em si mesmos" (RODRIGUES; GARMS, 2007, p. 14).

Aqui, percebe-se uma concepção de educação que leva em conta uma prática minimamente estruturada (mas não inflexível) pelo professor, pois do contrário cair-se-ia em um contexto de sala em que todos os momentos são livres, soltos e obras do acaso.

Rodrigues e Garms (2007) afirmam que, ao se pensar uma prática pedagógica para a Educação Infantil, deve-se deixar de lado a concepção de que para atuar com crianças pequenas o professor deve agir com total espontaneidade, sem planejar suas intervenções, como se suas práticas pudessem atrapalhar o curso do desenvolvimento da criança. As autoras acreditam que educar é, sobretudo, orientar o desenvolvimento humano, de modo que "as atividades têm que ser planejadas para incitar um caminho estimulador que deixe evidente para o educador o que se quer expor para a criança, como obter e como avaliar o que de fato ocorreu" (p. 3).

Redin (2007, p. 84) vai ao encontro dessas ideias, quando aponta que "não podemos assentar nossas propostas em um espontaneísmo ingênuo, que supõe que a criança aprende sozinha e naturalmente". Todos os aprendizados das crianças são mediados pela cultura e pelas relações que ela estabelece com as pessoas e os ambientes. Por outro lado, a autora diz que não podemos cair no extremo oposto, de achar que o professor pode controlar e determinar os aprendizados das crianças. Sua proposta é que o planejamento evidencie o papel do professor como mediador, que levanta uma série de possibilidades para que a ação educativa aconteça.

0 planejamento deve ser pensando, então, nessa perspectiva: permitir ao professor a visualização de uma trajetória possível a ser seguida, sem, no entanto, precisar estar preso a ela. É como se ele traçasse um caminho em um mapa, ciente de que as próprias contingências do caminhar podem fazer com que seja necessário mudar a rota. 


\section{0 planejamento é um processo contínuo, em que os planos não são tentativas de previsões, mas fornecem organizadores provisórios e passíveis de mudanças.}

"Um bom planejamento é vivo; deve ter um espaço para o inédito." Michele, coordenadora pedagógica.

"Um bom planejamento tem que garantir a visão de um todo amplo e suficiente para que eu possa mudá-lo a partir das demandas." César, professor.

"Planejar detalhadamente cada dia não é necessariamente efetivo." César, professor.

Planejar para em seguida mudar. Os professores entrevistados dizem que não planejam como se quisessem fazer uma previsão do que vai acontecer. Eles planejam para ter uma referência organizadora de suas práticas, que pode e deve ser passível de mudanças, a partir das mais diversas demandas. Acreditam que não adiantaria planejar exaustivamente cada momento do dia, se eles se mostram conscientes das inúmeras situações inusitadas que podem os fazer "sair" do previamente pensado.

\footnotetext{
Planejar atividades não se refere propriamente à previsão de uma sequência de atos que serão obrigatoriamente seguidos, cabendo ao educador controlar para que as crianças participem obedientemente destas, pois essa atitude em nada contribui para o processo de desenvolvimento infantil. Muito pelo contrário, posturas inflexíveis como esta recaem no que Rosa (1994) chama de "rotinização", ou seja, uma prática que adota uma sequência de procedimentos e tarefas cotidianas mantidos sempre da mesma forma (RODRIGUES, 2012, p. 93-94).
}

Ainda que não deva servir para engessar a prática docente, com longos detalhamentos e especificações, o plano tem uma função muito importante nesse processo, como será tratado a seguir. Por ora, vale referir que o entendo como um documento aglutinador de ideias e de reflexões sobre o processo, com possibilidades de intervenções futuras que devem ser desenhadas permitindo flexibilidade, a fim de que o inusitado das situações reais seja levado em conta.

O planejamento deve ser entendido como um exercício de imaginação que não está pautado em uma prescrição linear, mas que permite idas e vindas, sendo mais um desenho sinuoso do que uma reta. Nenhum plano pode ser preconcebido, fechado, hierarquizado. Desse modo, "planejar não é determinar caminhos, mas direções", uma vez que se leva em conta que sua 
concretização só se dá em um espaço e tempo determinados, atravessado pelas mais diversas relações e sofrendo influência direta das crianças e de suas culturas (REDIN, 2007, p. 89). A asserção seguinte fala exatamente disto: do quanto as manifestações do grupo de crianças devem ser levadas em conta no planejamento do professor.

\section{0 planejamento deve dosar a intencionalidade do professor e os interesses $\mathbf{e}$ as necessidades das crianças, de modo que expresse a identidade da turma, da professora e da instituição.}

"O planejamento garante que o professor consiga se colocar frente ao grupo, com a sua intencionalidade, porque ele tem uma e acho que ele tem que ter, e ao mesmo tempo dar a ele um espaço de ouvir essa criança, de ver o que essa criança lhe retorna, para que possa reelaborar o planejamento." Roberta, diretora.

"Acho que a maior observação das crianças permite que o planejamento seja feito em cima do que realmente é o maior interesse delas." Aline, professora.

"O planejamento deve ter a cara do grupo, da escola e da professora." Juliana, professora.

Essa asserção expressa um dos pontos que considero fundamentais para a elaboração de um bom planejamento: encontrar um equilíbrio entre a valorização dos interesses das crianças (entendendo que elas são sujeitos sociais e históricos e que têm suas próprias vontades e necessidades) e dos interesses da sociedade em relação às crianças (ou seja, o que nós adultos entendemos como importante para o aprendizado delas e sua formação enquanto cidadãos), que pode ser expressa pela intencionalidade pedagógica do professor.

Não há dúvida de que essa busca se fundamenta na concepção de que a criança é protagonista no seu processo de aprendizagem e que constrói significados na interação com o meio. Presente no discurso dos entrevistados e também nas propostas pedagógicas das instituições, tal conceito aparece bastante em voga na produção científica sobre o tema.

A Educação Infantil brasileira tem sofrido influências de autores da chamada "Sociologia da Infância", que pensam a socialização de modo interacionista, ou seja, as crianças são vistas como tendo um papel ativo na definição de sua própria condição social, nas 
relações que estabelecem. Elas não incorporam apenas papéis socialmente determinados, ou se treinam para a vida adulta; elas interferem no mundo social e também o constroem. As crianças são concebidas como atores sociais, sendo peças fundamentais nas relações que estabelecem (ALDERSON, 2005; SIROTA, 2001).

Nesse sentido, tem sido exaltada por inúmeros autores na realidade nacional [ver, por exemplo: (DELGADO; MULLER, 2005); (CRUZ, at al, 2008); (FARIA; DEMARTINI; PRADO, 2005) e (MULLER; CARVALHO, 2009)] a proposição de que a criança deve ter sua voz escutada tanto em pesquisas quanto no cotidiano das instituições de Educação Infantil. Esse é um princípio fundamental para a prática docente efetiva, e consequentemente para a atividade de planejamento. Corsino (2009) reafirma essa ideia ao referir:
Toda criança é um sujeito e nas suas relações está o tempo todo significando e recriando o mundo ao seu redor. A aprendizagem é a possibilidade de atribuir sentido às suas experiências. Planejar inclui escutar a criança para poder desenhar uma ação que amplie as suas possibilidades de produzir significados" (CORSINO, 2009, p. 117).

No entanto, tenho receio de interpretações aligeiradas acerca dessas concepções. Escutar a criança, permitir e respeitar suas produções culturais e valorizar a sua participação social não implica que os adultos a deixe solta, num contexto vazio, sem oferecer-lhe orientação e sem ter objetivos pedagógicos para as atividades.

Oliveira-Formosinho e Formosinho (2011) concebem o planejamento como um processo de negociação em que o professor busca debater e chegar a consensos com o grupo de crianças a respeito dos conteúdos curriculares, bem como do ritmo e das formas com que eles serão trabalhados.

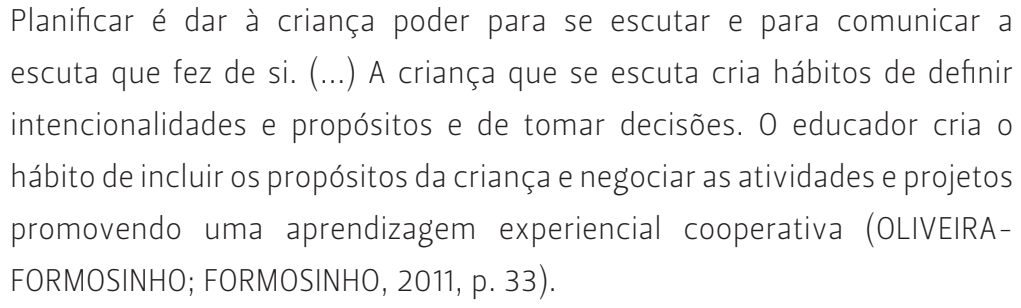

A fim de promover essa negociação entre as intenções do professor e os interesses das crianças, a observação e a escuta são fundamentais, sendo processos contínuos e cotidianos que devem sempre levar em conta o contexto em que as ações das crianças estão acontecendo. "É um processo de procura de conhecimento sobre as crianças, seus interesses, motivações, relações, saberes, 
intenções, desejos, modos de vida, realizada no contexto da comunidade educativa procurando uma ética da reciprocidade" (OLIVEIRA-FORMOSINHO; FORMOSINHO, 2011, p. 33).

Mas o que seriam esses interesses das crianças? Hedges (2007) estudou detalhadamente o tema e define que tais interesses são representados por atividades, brincadeiras, discussões e pesquisas das crianças que são espontâneas, automotivadas e derivadas de suas experiências sociais e culturais. Assim, os interesses das crianças são estimulados por vivências nas quais elas estão engajadas em sua família, comunidade e escola.

Em trabalho posterior, a mesma autora e colegas (HEDGES; CULLEN; JORDAN, 2011) afirmam que muito se tem escrito sobre a elaboração de um currículo centrado nos interesses das crianças. Entretanto, há ainda poucos estudos que descrevem esses interesses e como as professoras tomam conhecimento deles e os utilizam na construção do currículo. 0 artigo apresenta uma pesquisa qualitativa realizada em duas pré-escolas da Nova Zelândia que teve como objetivo investigar quais são os interesses das crianças e como os professores reconhecem e se comprometem com eles nas atividades pedagógicas. E também como os professores selecionam os interesses das crianças para fazerem parte da construção de um currículo sociocultural que contemple interações de aprendizagem tanto planejadas como espontâneas.

Os resultados dessa pesquisa indicam que os interesses das crianças estão relacionados a sua participação intencional na família e na comunidade, encapsulada pela noção de "funds of knowledge" (fundos de conhecimento) (GONZALES et al, 2005 apud HEDGES; CULLEN; JORDAN, 2011). Esse conceito permite aos professores conhecer os interesses das crianças e estender o planejamento curricular para além de um ambiente de aprendizagem, centrado nas crianças e lúdico. Estudar os "fundos de conhecimento" possibilita uma perspectiva mais analítica dos interesses das crianças do que aqueles modelos teóricos baseados apenas no reconhecimento das escolhas delas durante as atividades de brincadeira. Os professores precisam estar envolvidos com as famílias e comunidades de múltiplas formas a fim de entenderem mais profundamente o que motiva as crianças. Muitas vezes eles reconhecem os interesses delas apenas baseados nas atividades de brincadeira, deixando de lado outros mais profundos (HEDGES; CULLEN; JORDAN, 2011).

Perceber e valorizar os "fundos de conhecimento" das crianças 
e, consequentemente, seus interesses requer uma prática docente voltada para um processo de reflexão sustentado na escuta e na observação das crianças. Muitas vezes as ações "observar e escutar" são confundidas com apenas "ver e ouvir". As duas primeiras requerem uma postura analítica e interpretativa por parte do professor, enquanto apenas "ver e ouvir" remete a uma perspectiva simplificadora das ações e pensamentos das crianças.

Gostaria aqui de resgatar a base da pedagogia proposta por Paulo Freire, que é a construção coletiva de conhecimento, tendo como meio o diálogo constante entre o educador e os educandos. Destaco seu pensamento quando afirma que "formar é muito mais do que puramente treinar o educando" (p. 14) e que "ensinar não é transferir conhecimento, mas criar as possibilidades para a sua produção ou a sua construção" (p. 22). Ensinar e aprender são processos indissociáveis, e só existe aprendizado quando há relação. Ser um educador democrático é, antes de tudo, estimular a capacidade crítica, a curiosidade e a insubmissão do educando. É tarefa do professor, em uma prática educativo-crítica, criar uma situação favorável para que todos, educador e educandos, possam se assumir enquanto atores sociais, humanos, críticos, comunicativos, transformadores. Para isso, é fundamental que o professor lute para manter diálogo com seus educandos, que acontece quando ele estimula os questionamentos e é receptivo aos posicionamentos do grupo (FREIRE, 1996).

Esse diálogo constante é o que possibilita ao professor encontrar um equilíbrio entre suas intenções e os interesses das crianças. Concluo a partir dos dados deste estudo, porém, que esse equilíbrio é difícil de ser alcançado pelo professor ao planejar, ainda que possa estar presente no seu discurso e nos currículos em que se baseia. Na atividade de planejar, uma série de saberes (teóricos e vivenciais) são utilizados pelo professor, e são eles que darão o tom do plano e da própria atuação do docente, como descrito na próxima asserção.

\section{Os saberes do professor se associam e conduzem o ato de planejar.}

"O professor acaba trabalhando com aquilo que ele gosta mais. Ele também faz aquilo que ele pode. Acho que o planejamento do professor acaba ficando uma coisa muito pessoal. O que eu gosto eu faço, o que eu não gosto eu não faço." Nadine, diretora. 
"O professor tem que ter repertório, porque, se não tiver, fica na mesmice. Daí não acompanha o ritmo das crianças." Madalena, professora.

Ao se lançar na tarefa de sistematizar conteúdos, proporcionar experiências, articular linguagens expressivas por meio de atividades restritas a determinados tempos, espaços, contextos, o professor planeja. Planeja utilizando sua experiência profissional, sua percepção acerca das vontades e necessidades de seu grupo de crianças, seu referencial teórico e suas concepções de aprendizagem e de infância.

0 planejamento representa sempre uma opção, que expressa a subjetividade do professor. A prática pedagógica nunca pode ser considerada neutra ou passível de ser mecanicamente reproduzida, pois "entre o global e o local, entre o social e o individual, entre a teria e a prática, existe sempre um atravessamento de sentidos e significados que é singular, intransferível" (REDIN, 2007, p. 83).

Segundo o conteúdo trazido pelos entrevistados, o repertório do professor é composto por saberes oriundos de experiências profissionais passadas, de formações dentro e fora da escola, de cursos diversos (principalmente os relacionados às artes) e de experiências de vida (relacionadas a gostos e aptidões). Como os entrevistados sublinharam, o professor leva para seu trabalho com as crianças o que ele gosta, o que ele sabe e o que ele sente ser importante. Os interesses pessoais se associam ao perfil profissional, porque o professor é a mesma pessoa em casa e na escola.

Pode-se dizer que a prática docente está baseada em diversos saberes, provenientes de múltiplas experiências vividas pelo professor. Tardif (2010) pesquisou durante muitos anos os saberes que são mobilizados na prática docente, postulando que tais saberes estão sempre relacionados ao contexto de trabalho do professor e seus condicionantes.

\footnotetext{
O saber dos professores é o saber deles e está relacionado com a pessoa

e a identidade deles, com sua experiência de vida e com sua história profissional, com as suas relações com os alunos em sala de aula e com os outros atores escolares na escola, etc. Por isso, é necessário estudálo relacionando-o com esses elementos constitutivos do trabalho docente (p. 11).
}

De acordo com esse autor, o saber docente é plural e heterogêneo, pois está baseado em saberes diversos, tais como os 
saberes disciplinares, curriculares e experienciais e os oriundos da formação profissional. Para o exercício da profissão são integrados conhecimentos e manifestações do saber-ser e do saber-fazer de natureza diversa e provenientes de experiências variadas.

Ensinar é mobilizar uma ampla variedade de saberes, reutilizando-os no trabalho para adaptá-los e transformá-los pelo e para o trabalho. A experiência de trabalho, portanto, é apenas um espaço onde o professor aplica saberes, sendo ela mesma saber do trabalho sobre saberes, em suma: reflexividade, retomada, reprodução, reiteração daquilo que se sabe naquilo que se sabe fazer, a fim de produzir sua própria prática profissional (TARDIF, 2010, p. 21).

Tardif apresenta uma tipologia de classificação dos saberes dos professores: pessoais; provenientes da formação escolar anterior; provenientes da formação profissional para o magistério; provenientes dos programas e livros didáticos usados no trabalho e provenientes de sua própria experiência na profissão, na sala de aula e na escola. Ele refere que os saberes docentes são caracterizados por sincretismo, ou seja, quando associados em conjunto não possuem uma coerência teórica ou conceitual, "mas pragmática e biográfica: assim como as diferentes ferramentas de um artesão, eles fazem parte da mesma caixa de ferramentas, pois o artesão que as adotou ou adaptou pode precisar delas em seu trabalho" (p. 65). Desse modo, ao agir o professor lança mão de vários saberes compósitos, conforme a situação. Não se pode pensar nos saberes docentes como aplicáveis dentro de uma racionalidade técnica quando uma situação concreta pode ser resolvida com um conhecimento específico previamente adquirido.

Nesse sentido, Oliveira e colaboradoras (2006, p. 548) afirmam:

Existe hoje um consenso segundo o qual se afirma que o professor não deve ser visto apenas como um técnico em questões de ensino, mas como pessoa em processo de construir mudanças em sua identidade e no "sentido de si".

A identidade do professor certamente é constituída em várias esferas de sua vida, mas muito fortemente é influenciada pelas situações que ele vivencia dentro da escola, como é tratado a seguir.

A reflexão coletiva dentro da escola e a ação do coordenador pedagógico ajudam o professor a planejar. 
"O contato com as outras colegas e com a coordenadora é muito enriquecedor. Cada professora tem a chance de contar o que está fazendo, como está trabalhando naquele momento." Bianca, professora.

"Eu tenho bastante autonomia para trabalhar, mas a coordenadora pedagógica me dá pistas do que eu devo fazer e eu percebo que ela confia e incentiva o meu trabalho. Bem diferente da coordenadora que eu tinha na escola particular, que parecia não se importar com o meu trabalho." Juliana, professora.

A fala de Juliana, a mais jovem na profissão e na rede, expressa a influência que a coordenadora pedagógica teve em sua formação profissional. Certamente, os momentos de formação e de planejamento dentro das unidades têm um impacto na construção da identidade do professor.

É interessante apontar que a maioria dos professores entrevistados diz que aprendeu a fazer planejamento quando começou de fato a trabalhar, e o aprendido na faculdade de pedagogia ou no curso de magistério teve pouco auxílio em seu planejar. Alguns entrevistados trouxeram também a ideia de que ainda estão aprendendo a fazer o planejamento. Penso que isso esteja ligado a características próprias do ato de planejar: o inacabamento e a continuidade. 0 planejamento parece ser um processo aprendido e construído à medida das realidades vividas no exercício da profissão de professor.

Mesmo sabendo que a decisão final do planejamento recai sobre o professor, penso que essa atividade não possa ser um trabalho isolado de reflexão dele sobre seu grupo, mas que deva ser uma atividade integrada, contando com a participação da criança e dos outros profissionais da instituição. Há, portanto, a necessidade de se afirmar claramente a interdependência com outros setores da instituição, com outras professoras, com as possibilidades e limitações físicas e administrativas. Nesse sentido, o papel do coordenador como articulador desses momentos coletivos de formação e reflexão dentro da escola é ainda mais importante.

Ahmad e Werle (2011, p. 11) discorrem sobre o papel do coordenador pedagógico na construção do planejamento dos professores em uma escola de Educação Infantil ligada à Universidade Federal de Santa Maria, no Rio Grande do Sul. Elas relatam que o coordenador participa de reuniões semanais com grupos de professores, quando eles têm a chance de contar sobre os projetos que estão sendo desenvolvidos com as crianças, refletir 
sobre a prática, problematizando as situações vividas e buscando soluções. Essas reuniões, de acordo com as autoras, têm ajudado a melhorar significativamente a qualidade tanto do planejamento quanto do registro realizados pelos professores. Isso acontece porque a atuação do coordenador ajuda a organizar as práticas pedagógicas da escola e articular os vários profissionais que atuam nela.

Essa articulação é um grande um desafio para o coordenador pedagógico, que tem de criar uma linha mestra de trabalho que seja base do planejamento, quando existe uma heterogeneidade de trajetórias, de saberes e de perspectivas teóricas dos professores. Em algumas situações não se consegue ter o consenso do grupo em concepções básicas e o trabalho de reflexão compartilhada fica, então, mais difícil. Pode ser desgastante para o grupo ter que repetidas vezes discutir e combinar princípios comuns de trabalho. De todo modo, as discussões têm um papel fundamental no processo de aprendizagem do professor.

0 planejamento como atividade coletiva ajuda o professor a desenvolver uma atitude crítica, pois se configura como o momento de reflexão sobre a prática docente. E por isso pode ser pensado como oportunidade de aprendizagem para o professor, que ao planejar exercita seu olhar sobre a prática, conhecendo melhor o seu grupo de crianças e detectando dificuldades e possíveis soluções (OSTETTO, 2000).

Corsino (2009, p.119) vai ao encontro dessa ideia: "0 planejamento é o lugar de reflexão do professor, que, a partir de suas observações e registros, prevê ações, encaminhamentos e sequências de atividades, organiza o tempo e o espaço, seleciona e disponibiliza materiais".

Oliveira e colaboradoras (2006), ao relatarem as experiências de formação de professoras de creche do programa ADI - Magistério da SME de São Paulo, contam que as professoras sentiram uma modificação em suas práticas na medida em que começaram a planejar as atividades. Essa mudança está associada a se sentirem mais identificadas, como professoras, a profissionais que planejam, organizam, registram e refletem sobre suas práticas. "Faz parte do ser professor planejar e organizar a ação pedagógica; saberes que são tomados como referência para se compreender aquilo que era inadequado no passado" (p. 558). 


\section{A elaboração do plano requer tempo e método.}

"Para eu preparar uma atividade de qualidade, eu tenho que pesquisar, porque tem muitos assuntos que interessam as crianças que eu não domino. Esse tempo que leva para pesquisar é a minha maior dificuldade." Madalena, professora.

"Com o correr do tempo, tem atividades que você não precisa mais planejar. Se planejar é escrever no papel ou no computador, eu não planejo assim." César, professor.

Essa última asserção diz respeito às formas com que a atividade de planejar acontece para esses profissionais. Alguns deles mencionaram que a falta de tempo é um dos fatores que mais prejudicam o seu planejamento. Madalena, por exemplo, que costuma pesquisar sobre os assuntos a serem tratados com as crianças, se ressente de não ter mais tempo.

Muitos entrevistados referiram que quase não usam o espaço dado dentro da escola para essa atividade, ainda que ele sirva como momento de reflexão. As ideias surgem de forma inesperada em diversas situações e o próprio ato de traçar o plano é feito em casa. Com exceção de uma professora, os diários dos professores apresentavam mais um relato do que aconteceu do que propriamente um projeto futuro. Isso demonstra que, em certa medida, o plano diário ou semanal estava mais na cabeça do professor do que no papel.

Nas duas instituições os professores eram solicitados a elaborar planos para os bimestres e as equipes gestoras não exigiam a confecção de planos escritos mais frequentes e sistematizados. A revisão dos planos dos professores pelas coordenadoras pedagógicas era feita por meio de reunião (individual e/ou coletiva) e por apropriação dos planos bimestrais. Refletindo sobre essa forma de organização ficam os seguintes questionamentos: será que apenas o plano bimestral é suficiente para organizar a prática pedagógica? 0 quanto a prática pedagógica seria beneficiada caso um acompanhamento da equipe gestora acontecesse de modo mais sistemático e formal, com a exigência de planos menos espaçados aos professores?

Dados semelhantes foram encontrados na pesquisa de Scmitt, Berner e Rausch (2006). Elas buscaram investigar a coerência entre o discurso das professoras e seus planos escritos. Para isso, entrevistaram vinte professoras de Educação Infantil no município de Blumenau, em Santa Catarina, acerca do registro 
que elas fazem do seu planejamento e analisaram esses registros. Oito das professoras entrevistadas afirmaram fazer o registro do planejamento. Entretanto, ao analisarem os planos escritos, as pesquisadoras descrevem que elas fazem apenas relatos de fatos ocorridos durante o dia em seus cadernos, não havendo nenhuma evidência de plano.

De algum modo, a falta de um plano registrado no papel pode apontar para situações bastante diferentes: o professor está muito seguro do que pretende fazer, e o relato do dia anterior e o plano bimestral já lhe servem de base para ter clara a continuidade a ser dada no dia seguinte, sem necessidade de traçar objetivos e meios; o professor trabalha no improviso e o planejamento é tido como um processo informal, que não necessita ser registrado no papel pela possibilidade de mudanças a qualquer momento; o professor atrela o seu plano a uma rotina engessada, que não permite mudanças, não sendo necessário ter um plano para cada dia, pois ele previamente já sabe o que irá acontecer.

Percebi, nas observações, momentos de improviso por parte do professor, principalmente nas salas de Bianca e César. A impressão que tive é que eles haviam planejado uma atividade para o dia e, uma vez ela feita, buscavam preencher o tempo com atividades soltas. Aline, Juliana e Madalena pareciam ter uma linha mais estruturada para o dia, apesar de apenas Aline ter um registro do que pretendia fazer de antemão.

Há que se encontrar um equilíbrio entre o improvisado e o pensado previamente, pois eles são necessários para o dinamismo desejável do cotidiano na Educação Infantil. Nesse sentido, o plano escrito tem muito a contribuir, já que o ato de sentar e escrever sobre o planejamento ajuda o professor a ter novas ideias, a avaliar práticas e permitir que um "improviso consciente" faça parte de sua prática. Escrever é sempre um processo de conscientização e determinação de verdades provisórias. Fica o questionamento: e se esses professores em seus diários de bordo, juntamente com o ocorrido, detalhassem o plano para o próximo dia ou próxima semana? Surgiriam novas ideias? Facilitaria a avaliação do grupo e de seu trabalho? As coordenadoras pedagógicas teriam uma noção mais nítida das intenções do professor?

Uma coisa é certa: a composição do plano escrito profissionaliza o trabalho docente, documentando intenções, linhas de trabalho e a identidade do professor e do grupo em um dado momento. Concordo inteiramente com Scmitt, Berner e Rausch (2006, p. 11-12): 
Com a preocupação na busca da qualificação no trabalho desenvolvido com crianças pequenas, o registro do planejamento pode e deve ser um instrumento norteador para o educador infantil. (...) Toda ação educativa é marcada pela intencionalidade. 0 registro marca o delineamento dessa ação educativa e permite melhor organização da práxis docente.

Retomo aqui o conceito de práxis docente proposto por OliveiraFormosinho e Formosinho (2011), entendendo que o planejamento e seu registro (plano) organizam de fato essa conjunção entre ações, teorias e crenças e representam o processo mediador entre o currículo, os saberes do professor, os interesses das crianças e o que já foi vivido pelas turmas.

\section{Considerações finais}

Por fim, é importante que se aponte que a atividade de planejamento requer dedicação e empenho por parte do professor e que as redes públicas devem prever, no contrato de trabalho dos docentes, tempo semanal para essa atividade. Concluí com este estudo que o planejamento é uma atividade complexa que precisa ser apoiada e subsidiada pelas instituições e pelas redes de ensino, já que requer o esforço do professor para executar pelo menos três ações: escrever, debater e pesquisar.

A atividade escrita pode ser entendida como o momento de sintetizar o vivido e de projetar o futuro. Essa ação reflexiva ajuda a organizar memórias e visualizar planos. Os professores participantes deste estudo têm em seu dia a dia o hábito da escrita, ainda que poucos apresentem planos futuros em seus registros. Se desafiados a planificar o cotidiano, que efeitos esse ato teria sobre suas práticas? Essa é uma questão que fica em aberto, talvez para a sequência de outros estudos que analisem a prática de professores que efetivamente registram seus planos no papel.

Talvez os planos dos professores entrevistados se organizem mais no debate com outros colegas e com as coordenadoras pedagógicas do que no papel. Esses horários de reunião semanais usados para planejamento, na perspectiva dos professores, são muito valiosos. Ainda que a maioria deles tenha relatado não sair dali com um plano pronto, as ideias trocadas com o grupo suscitam reflexões acerca do que já aconteceu e do que está por vir. Nesse sentido, a impossibilidade de os professores que trabalham com a mesma turma em turnos diferentes se reunir semanalmente é bastante prejudicial ao planejamento, que se espera conjunto, já que se trata da prática com as mesmas crianças. De todo modo, 
esses horários de construção coletiva ajudam o professor a pensar a sua prática, não só porque a discute, mas também porque escuta os relatos de outros professores, que podem inspirar a buscar alternativas de trabalho com seu grupo.

A terceira ação, pesquisar, diz respeito a uma postura de buscar subsídios para sua prática, ou seja, informações sobre determinado assunto, estratégias de trabalho com as crianças, livros, materiais e brinquedos com propósitos específicos e assim por diante. Pesquisar está intimamente ligado a dois aspectos: a intencionalidade do professor e os interesses das crianças. Pela observação do trabalho dos professores, foi possível perceber que as opiniões das crianças eram levadas em conta nas duas EMEls, ainda que elas tivessem níveis muito variados de influência direta nos planejamentos dos professores. De modo geral, é possível constatar que a atuação das crianças na transformação do cotidiano foi valorizada em níveis e formas diversos pelos professores.

\section{REFERÊNCIAS}

ABUCHAIM, Beatriz de Oliveira. Currículo, planejamento pedagógico e cotidiano na pré-escola: do prescritoplanejado ao experienciado-vivido. Tese (Doutorado em Educação: Currículo). Programa de Pós-Graduação em Educação: Currículo, Pontifícia Universidade Católica de São Paulo, 2012.

AHMAD, L.; WERLE, K. Planejamento na Educação Infantil: uma construção mediada pela coordenação pedagógica no núcleo de Educação Infantil Ipê Amarelo. Anais do X Congresso Nacional de Educação - EDUCERE, Curitiba, Pontifícia Universidade Católica do Paraná, 2011. Disponível em: http://educere.bruc.com.br/CD2011/pdf/5935_3891. pdf. Acesso em: 01/09/2012.

ALDERSON, P. As crianças como pesquisadoras: os efeitos dos direitos de participação sobre a metodologia de pesquisa. Educação e Sociedade, Campinas, v. 26, n. 91, p. 419-442, Maio/Ago., 2005.

BARDIN, L. Análise de conteúdo. São Paulo: Martins Fontes, 1977. 
BOTTOMORE, W. Dicionário do Pensamento Marxista. Rio de Janeiro: Zahar, 1988.

CAMPOS, M.M. et al. A gestão da Educação Infantil no Brasil (Relatório Final). São Paulo: Fundação Carlos Chagas; Fundação Victor Civita, 2012. Disponível em: http://www.fvc.org.br/estudos-e-pesquisas/2011/pdf/ relatoriofinaleducacaoinfantil.pdf. Acesso em 18/10/2012.

CAMPOS, M.M. et al. Educação Infantil no Brasil: avaliação qualitativa e quantitativa (Relatório Final). São Paulo: Fundação Carlos Chagas, 2010. Disponível em: http://www. fcc.org.br/pesquisa/eixostematicos/educacaoinfantil/pdf/ relatorio_final.pdf Acesso em 20/05/2011.

CORSINO, Patrícia. Considerações sobre o planejamento na Educação Infantil. In: CORSINO, P. Educação Infantil: cotidiano e políticas. Campinas, SP: Autores Associados, 2009, Cap. 8, p. 117-121.

CRUZ, S.H.V. (org.). A criança fala: a escuta da criança em pesquisas. São Paulo: Cortez, 2008.

DELGADO, A.C.C.; MULLER, F. Sociologia da infância: pesquisa com crianças. Educação e Sociedade, Campinas, v. 26, n. 91, p. 351-360, maio/ago., 2005.

FARIA, A.L.G. de; DEMARTINI, Z. de B.F.; PRADO, P.D. (Orgs.). Por uma cultura da infância: metodologias de pesquisa com crianças. São Paulo: Autores Associados, 2005.

FREIRE, P. A pedagogia do oprimido. Rio de Janeiro: Paz e Terra, 1987.

FREIRE, P. Pedagogia da autonomia: saberes necessários à prática educativa. São Paulo: Paz e Terra, 1996.

GIMENO SACRISTÁN, J. Currículo: Uma reflexão sobre a prática. Porto Alegre: Artmed, 2008.

GIMENO SACRISTÁN, J.; PÉREZ GÓMEZ, A.I. Compreender e transformar o ensino. Porto Alegre: Artes Médicas, 2007.

GUIMARÃES, Daniela. Princípios para planejar: a criança como protagonista. Brasília: MEC - Secretaria de Educação Básica e 
Secretaria de Educação a Distância, 2005 (Texto produzido para Livro de Estudo - Módulo IV (vol. I) do PROINFANTIL - MEC).

HEDGES, H. Funds of knowledge in early childhood communities of inquiry. 2007. Tese de doutorado, Massey University, Palmerston North, New Zealand. Disponível em: http://hdl.handle.net/10179/580. Acesso em:

HEDGES, H.; CULLEN, J.; JORDAN, B. Early years curriculum: funds of knowledge as a conceptual framework for children's interests. Journal of Curriculum Studies, Londres, v. 43, n. 2, p. 185-205, 2011.

MULLER, F.; CRAVALHO, A.M.A. (orgs). Teoria e prática na pesquisa com crianças: diálogos com William Corsaro. São Paulo: Cortez, 2009.

OLIVEIRA, Z.M.R. et al. Construção da identidade docente: relatos de educadores de educação infantil. Cadernos de pesquisa. São Paulo, v. 36, n. 129, set./dez. 2006. Disponível em: <http://www.scielo.br/pdf/cp/v36n129/a0336129.pdf>. Acesso em: 28/08/2012.

OLIVEIRA-FORMOSINHO, J.; FORMOSINHO, J. A perspectiva pedagógica da Associação Criança: a pedagogia em participação. In: OLIVEIRA-FORMOSINHO, J.; GAMBÔA, R. O trabalho de projeto na Pedagogia-em-Participação. Porto: Porto Editora, 2011, cap. 1, p. 11-45.

OSTETTO, L.E. Planejamento na Educação Infantil: mais que a atividade, a criança em foco. In: OSTETTO, L. E. (Org.) Encontros e encantamentos na Educação Infantil. 2 ed. São Paulo: Papirus, 2000, p. 175-200.

OSTETTO, L.E.. Planejamento e prática pedagógica na Educação Infantil: conhecer as crianças, construir diálogos, tecer possibilidades. In: Aline Sommerhalder. (Org.). A Educação Infantil em perspectiva: fundamentos e práticas docentes. $1^{a}$ ed. São Carlos - SP: EDUFSCar, 2015, v. 1, p. $105-131$.

REDIN, M.M. Planejamento na Educação Infantil com um fio de linha e um pouco de vento. In: REDIN, E.; MULLER, F.; REDIN, M.M. (Orgs.) Infâncias: cidades e escolas amigas das crianças. Porto Alegre: Mediação, 2007, cap. 6, p. 83-99. 
RODRIGUES, S.A.; GARMS, G.M.Z. Intencionalidade da ação educativa na Educação Infantil: a importância da organização do tempo e do espaço das atividades. Nuances: Estudos sobre Educação, Presidente Prudente, FCT/UNESP, ano XIII, v. 14, n. 15, p. 123 - 138, jan./dez., 2007.

RODRIGUES, S.A. As rotinas e a formação dos enredos pedagógicos na Educação Infantil. In: RODRIGUES, S.A.; GARMS, G.M.Z. (Orgs.) Temas e dilemas pedagógicos da Educação Infantil: desafios e caminhos. Campinas: Mercado das Letras, 2012, p. 91-113.

SCMITT, A.; BERNER, F.; RAUSCH, R. Registro do planejamento na Educação Infantil. UniRevista, São Leopoldo/RS, v. 1, n. 2, abril, 2006.

SIROTA, R. Emergência de uma sociologia da infância: evolução do objeto e do olhar. Cadernos de Pesquisa, São Paulo, n. 112, p. 7-31, mar., 2001.

TARDIF, M. Saberes docentes e formação profissional. Petrópolis: Vozes, 2010.

YIN, R. Estudo de caso: planejamento e métodos. Porto Alegre: Bookman, 2005.

Recebido em: 17/08/2016

Revisto em: 27/10/2016

Aceito em: 09/11/2016

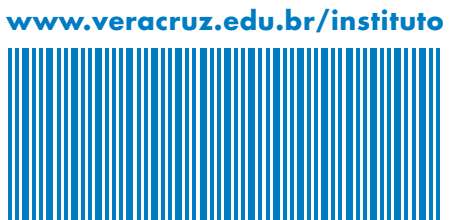

